\title{
Validitas Modul Elektronik untuk Mata Kuliah Pengukuran dan Instrumen
}

\author{
Muhammad Agung ${ }^{1 *}$ Fivia Eliza ${ }^{1}$ \\ ${ }^{1}$ Jurusan Teknik Elektro, Fakultas Teknik, Universitas Negeri Padang \\ Jln. Prof. Dr. Hamka Air Tawar Padang 25131 Indonesia \\ *mhdagung270@gmail.com
}

(Diajukan: 10 Mei 2021, direvisi: 26 Mei 2021, disetujui: 03 juni 2021)

\begin{abstract}
Abstrak
Penelitian ini dilatarbelakangi oleh terbatasnya media pembelajaran yang menunjang pembelajaran daring pada mata kuliah Pengukuran dan instrumen di Jurusan Teknik Elektro FT UNP. Mata kuliah ini merupakan mata kuliah dasar yang sangat penting untuk menunjang mata kuliah lain di semester berikutnya. Dari hasil observasi diketahui bahwa dalam pembelajaran daring yang menggunakan LMS mahasiswa kesulitan dalam menemukan referensi untuk menyelesaikan tugas yang diberikan. Hal ini terjadi karena masih terbatasnya sumber belajar online yang dapat diakses oleh para mahasiswa untuk mata kuliah ini. Oleh karena itu penelitian ini bertujuan untuk menghasilkan modul elektronik yang valid untuk mata kuliah pengukuran dan instrument. Modul elektronik yang dikembangkan diuji validitasnya dengan menggunakan angket validitas dan meminta pendapat ahli media dan ahli materi, lalu dianalisis dengan rumus uji validitas. Berdasarkan hasil analisis rata-rata angket validitas diperoleh tingkat validitas modul elektronik adalah termasuk kategori valid baik sebagai media pembelajaran maupun dari sisi materi. Maka dapat disimpulkan bahwa modul elektronik untuk mata kuliah Pengukuran dan Instrumen termasuk kategori valid dan dapat digunakan sebagai referensi dalam proses pembelajaran.
\end{abstract}

Kata Kunci: E-modul, validitas, online learning

\begin{abstract}
This research was motivated by the limited learning media that support online learning in the Measurement and instrument course in the Department of Electrical Engineering, FT UNP. This course is a basic course which is very important to support other courses in the following semester. From the observations it is known that in online learning using LMS students have difficulty finding references to complete the given assignments. This happens because there are still limited online learning resources that can be accessed by students for this course. Therefore, this study aims to produce a valid electronic module for measurement and instrument courses. The developed electronic module was tested for validity by using a validity questionnaire and asking for opinions from media experts and content material experts, then analyzed using the validity test formula. Based on the results of the average validity questionnaire analysis, the validity level of the electronic module is included in the valid category both as a learning medium and in terms of material. So it can be concluded that the electronic module for the Measurement and Instrument course is in the valid category and can be used as a reference in the learning process.
\end{abstract}

Keyword: E-modul, validity, online learning 


\section{PENDAHULUAN}

Pendidikan merupakan faktor utama dalam pembentukan pribadi manusia. Pendidikan juga di defenisikan sebagai salah satu bentuk perwujudan kebudayaan manusia yang dinamis dan syarat perkembangan sehingga perubahan dan perkembangan pendidikan seharusnya sejalan dengan perubahan budaya kehidupan [1]. Pendidikan memegang peranan yang sangat penting karena pendidikan merupakan instrumen terpenting untuk meningkatkan Sumber Daya Manusia. Salah satu upaya ntuk meningkatkan sumber daya manusia adalah dengan mengikuti jenjang Pendidikan formal dari jenjang terendah yaitu sekolah dasar sehingga sekolah menengah pertama dan sekolah menengah atas hingga perguruan tinggi [2].

Salah satu faktor eksternal penting yang mempengaruhi hasil belajar siswa yaitu faktor sekolah yang terdiri dari pendidik, peserta didik dan sarana prasarana sebagai alat penunjang pendidikan [3]. Sarana pendidikan merupakan mencakup semua peralatan dan perlengkapan yang secara langsung digunakan dan menunjang dalam suatu proses pendidikan harus sesuai dengan proses pembelajaran. Sedangkan prasarana pendidikan adalah fasilitas yang secara tidak langsung menunjang jalannya proses pendidikan [4][5].

Perguruan tinggi sebagai Lembaga Pendidikan yang menyelenggarakan pembelajaran mempunyai peranan penting dalam mentransfer pengetahuan dan keterampilan dari dosen ke mahasiswa. Peranan tersebut di harapkan dapat menghasilkan lulusan yang berkualitas dan kompeten di bidangnya khususnya untuk mahasiswa di jurusan Teknik Elektro Universitas Negeri Padang. Pendidik dalam hal ini dosen harus mampu menimbulkan semangat belajar mahasiswa karena masing-masing mahasiswa mempunyai pengalaman dan sifat yang berbeda-beda, hal itu mengharuskan desen untuk mengembangkan perangkat pembelajaran secara mandiri. Agar mahasiswa dapat mengasah kemampuannya dalam belajar maka bahan ajar yang mendukung proses pembelajaran. Salah satu media pembelajaran yang bisa digunakan adalah penggunaan modul. Akan tetapi modul cetak membuat proses pembelajaran kurang menarik, sedikit interaktif dan belum mampu menyampaikan pesan-pesan historis melalui gambar dan video.

Berdasarkan hasil Observasi selama bulan September - Oktober 2020 di jurusan Teknik Elektro pada mata kuliah Pengukuran dan Instrumen: (1) Dosen lebih mendominasi pembelajaran menggunakan metode konvesional yaitu ceramah dan pemberian tugas melalui elearning2.unp.ac.id; (2) Kurangnya variasi sumber belajar menyebabkan mahasiswa hanya mengumpulkan tugas seadanya, hanya mengutip dari internet tanpa sumber yang jelas. (3) Mahasiswa masih kurang termotivasi untuk mencari sumber tambahan untuk belajar. (4) Pembelajaran belum memanfaatkan kemajuan TIK khususnya internet dalam aktivitas pembelajaran secara optimal, terbatasnya sumber belajar online yang dapat diakses oleh para mahasiswa untuk menunjang pembelajaran.

Berdasarkan paparan tersebut maka diperlukan solusi untuk mengatasi permasalahan dalam pembelajaran mata kuliah pengukuran dan instrumen. Penggunaan bahan ajar berupa e-modul bagi peserta ddidik merupakan salah satu alternatif untuk meningkatkan penguasaan materi dan hasil belajar peserta didik [6]. E-Modul yang akan digunakan dalam pembelajaran harus diuji terlebih dahulu kevalidannya. E-Modul yang 
valid yaitu e-modul yang telah di periksa oleh pakar atau ahli sehingga dapat diketahui tingkat kelayakannnya [7].

Dunia Pendidikan perlu memanfaatkan kemajuan teknologi informasi yang memungkinkan seorang pengembangkan pembelajaran dalam mengubah penyajian bahan ajar, dalam hal ini modul cetak, menjadi modul yang dikemas dalam format digital, atau dikenal dengan istilah electronic modul (e-modul). E-modul merupakan pengembangan dari modul tercetak yang dapat dibaca pada sebuah personal komputer dan dirancang dengan menggunakan software [8]. Penggunaan e-modul dalam proses pembelajaran dapat menimbulkan manfaat atau nilai tertentu dari segi penggunaannya, karena dalam penggunaannya mahasiswa dapat belajar sesuai dengan kecepatan belajar mereka.

Peran e-modul disini adalah sebagai bahan ajar yang dirancang oleh dosen, yang nantinya digunakan oleh mahasiswa pada materi yang akan dipelajarinya. Mengembangkan bahan ajar sudah selayaknya merupakan kemampuan yang harus terus menerus ditingkatkan oleh setiap dosen. Jika seorang dosen tidak memiliki kemampuan mengembangkan bahan ajar yang bervariasi maka dosen akan terjebak pada situasi pembelajaran yang monoton dan cenderung membosankan bagi mahasiswa. Dengan adanya e-modul mahasiswa belajar secara mandiri dan peran dosen hanya sebagai fasilitator saja. Artinya, peran dosen tidak terlalu dominan, dosen harus dapat membantu mahasiswa dalam mengatasi kesulitan belajar, atau ia dapat menjadi mitra belajar untuk materi yang telah dirancang yang dikemas dalam bentuk e-modul. Selain itu, tampilan emodul yang menarik diharapkan dapat meningkatkan minat dan motivasi belajar mahasiswa sehingga hasil belajar mahasiswa pun dapat meningkat pula [9].

Kerangka e-modul pembelajaran yang terdiri dari deskripsi judul, kegiatan pembelajaran, tujuan pembelajaran, materi pembelajaran, video pembahasan materi, kesimpulan, latihan soal. Tugas latihan soal tediri dari soal pertanyaan yang bertujuan untuk mengukur tingkat pemahaman mahasiswa dalam proses pembelajaran yang diberikan oleh dosen [10]. Berdasarkan uraian diatas maka disusun suatu media pembelajaran yang berbentuk e-modul yang dapat memudahkan mahasiswa dalam belajar secara mandiri.

\section{METODE}

E-Modul yang akan digunakan dalam pembelajaran harus diuji terlebih dahulu kevalidannya. E-Modul yang valid yaitu e-modul yang telah di periksa oleh pakar atau ahli sehingga dapat diketahui tingkat kelayakannnya [7]. Proses validitas ini dilakukan dengan menyiapkan angket validitas dan diberikan kepada dua orang validator yang sudah ditetapkan sebelumnya dan dianggap ahli dalam bidang media pembelajaran dan ahli dalam materi pengukuran dan instrument. Validator media materi adalah dosen jurusan Teknik Elektro Fakultas Teknik Universitas Negeri Padang yang sudah sering mengampu mata kuliah media pembelajaran dan pengukuran dan instrumen.

Selanjutnya validator mengisi instrument penelitian berupa angket validasi yang memberi masukan dan saran terhadap e-modul yang telah dibuat. Untuk menentukan validitas produk yang dihasilkan digunakan perhitungan skala Likert [11]. Skor untuk setiap indikator adalah sepeti pada tabel 1 . 
Tabel 1. Indikator Skala Likert

\begin{tabular}{clc}
\hline No & \multicolumn{1}{c}{ Indikator } & Skor \\
\hline 1 & Sangat Setuju & 5 \\
2 & Setuju & 4 \\
3 & Netral & 3 \\
4 & Tidak Setuju & 2 \\
5 & Sangat Tidak Setuju & 1 \\
\hline
\end{tabular}

Nilai validasi diperoleh dengan cara:

$$
\text { Nilai Validasi }=\frac{\text { jumlah skor yg diperoleh }}{\text { jumlah skor maksimal }}
$$

Skor maksimum yaitu diperoleh dari:

$$
\mathrm{Y}=\text { Skor tertinggi } \mathrm{x} \text { Jumlah Item Angket }
$$

Setelah data angket dianalisis dan diperoleh hasil validitas, kemudian dapat diketahui nilai kevalidan dengan kategori seperti tabel 2.

Tabel 2. Kategori Kevalidan

\begin{tabular}{ccc}
\hline No & Tingkat Pencapaian & Kategori \\
\hline 1 & $81-100$ & Sangat valid \\
2 & $61-80$ & Valid \\
3 & $41-60$ & Cukup valid \\
4 & $21-40$ & Kurang valid \\
5 & $0-20$ & Tidak valid \\
\hline
\end{tabular}

\section{HASIL DAN PEMBAHASAN}

Validasi e-modul dilakukan oleh 2 validator yang terdiri dari 1 dosen ahli media dan 1 dosen ahli materi yang masing-masing dari Teknik Elektro Fakultas Teknik Universitas Negeri Padang. Berdasarkan hasil validasi, validator 1 yaitu dosen ahli media memberikan skor $90 \%$ sedangkan untuk dosen validator 2 dosen ahli materi memberikan skor 92\% dengan rata-rata sebesar 91\% dengan kategori sangat valid yang artinya emodul pembelajaran telah memenuhi syarat. Untuk lebih jelasnya bisa dilihat dari tabel 3.

Persentase Kevalidan Validator

\section{Validator 1}

$$
\mathrm{V} 1=\frac{81}{90} \times 100 \%
$$

Nilai validitas validator 1 terhadap e-modul pembelajaran e-modul adalah $90 \%$. Berdasarkan tabel persentase $90 \%$ dikategorikan valid.

Validator 2

$$
\mathrm{V} 2=\frac{83}{90} \times 100 \%
$$

Nilai validitas validator 2 terhadap e-modul pembelajaran e-modul adalah $92 \%$. Berdasarkan tabel persentase $92 \%$ dikategorikan valid 
Tabel 3. Rekapitulasi Hasil Analisis

\begin{tabular}{|c|c|c|c|}
\hline & Indikator & $\begin{array}{c}\text { Validator 1 } \\
\text { (Ahli Media) }\end{array}$ & $\begin{array}{c}\text { Validator } 2 \\
\text { (Ahli Materi) } \\
\end{array}$ \\
\hline \multirow{7}{*}{1} & 1 & 5 & 5 \\
\hline & 2 & 5 & 5 \\
\hline & 3 & 4 & 5 \\
\hline & 4 & 4 & 4 \\
\hline & 5 & 4 & 4 \\
\hline & 6 & 5 & 5 \\
\hline & 7 & 5 & 5 \\
\hline \multirow{5}{*}{2} & 8 & 4 & 5 \\
\hline & 9 & 4 & 5 \\
\hline & 10 & 4 & 4 \\
\hline & 11 & 4 & 4 \\
\hline & 12 & 5 & 5 \\
\hline \multirow{12}{*}{3} & 13 & 4 & 5 \\
\hline & 14 & 5 & 4 \\
\hline & 15 & 5 & 4 \\
\hline & 16 & 4 & 5 \\
\hline & 17 & 5 & 5 \\
\hline & 18 & 5 & 4 \\
\hline & Perolehan Skor & 81 & 83 \\
\hline & Skor Maksimum & 90 & 90 \\
\hline & Nilai Kevalidan & 0,9 & 0,92 \\
\hline & Persentase & $90 \%$ & $92 \%$ \\
\hline & Rata-rata & \multicolumn{2}{|c|}{$91 \%$} \\
\hline & Kategori & Valid & Valid \\
\hline
\end{tabular}

\section{KESIMPULAN DAN SARAN}

Berdasarkan hasil penelitian dan pembahasan diatas, maka dapat disimpulkan bahwa e-modul pembelajaran Pengukuran dan Instrumen sebagai media pembelajaran di jurusan Teknik Elektro Fakultas Teknik Universitas Negeri Padang sudah dinyatakan valid berdasarkan uji validitas e-modul pembelajaran dengan perolehan skor yang di dapat rata-rata $91 \%$.

\section{REFERENSI}

[1] Amri. Sofan. 2013. Pengembangan \& Model Pembelajaran Dalam Kurikulum 2013. Jakarta: PT. Prestasi Pustakakarya.

[2] Anggita Rachmi. 2020. PENGEMBANGAN E-MODUL BERBASIS ANDROID MATA KULIAH STRUKTUR BETON II. Jurnal Pendidikan Teknik Sipil

[3] Slameto,Belajar Dan Faktor - Faktor Yang Mempengaruhi. Jakarta: Rineka Cipta, 2010.

[4] Yermon and F.Eliza,Pengembangan Modul Pembelajaran Dasar Listrik Dan Elektronika Untuk Kelas X TITL Di SMK Negeri 1 Padang. JTEV.Vol 06.No 02,302-203,2020

[5] I Gede Sudarma, I Ketut Resika Arthana , \& I Gede Partha Sindu. 2017. Pengembangan E-Modul Dengan Model Problem Based Learning Mata Pelajaran Pemrograman Dasar Kelas XI Teknik Komputer Dan Jaringan Di SMK Negeri 3 Singaraja. Kumpulan Artikel Mahasiswa Pendidikan Teknik Informatika

[6] D. Mahadiraja and Syamsuarnis,Pengembangan Modul Pembelajaran Berbasis Daring pada Mata Pelajaran Instalasi Penerangan Listrik Kelas XI Teknik Instalasi 
Tenaga Listrik T.P 2019/2020 di SMK Negeri 1 Pariaman, JTEV (Jurnal Tek. Elektro Dan Vokasional), Vol.06.No.01,2020.

[7] H.G.Syafli, Administrasi Sarana Dan Prasarana.Padang,2020.

[8] Rifmasari, Yessi. 2010. Penggunaan e-Modul Sebagai Sahan Aar Terhadap Hasil Belajar Siswa Pada Mata Pelajaran Teknologi Informasi dan Komunikasi Di Sekolah Menengah Atas. Skripsi Sarjana Pada FIP UPI Bandung : Tidak Di Terbitkan.

[9] Anggita Rachmi. 2020. PENGEMBANGAN E-MODUL BERBASIS ANDROID MATA KULIAH STRUKTUR BETON II. Jurnal Pendidikan Teknik Sipil

[10] A.Alimin And H.Effendi, Pengembangan Modul Pembelajaran Berbasis Daring Pada Mata Diklat Intalasi Penerangan Listrik Kelas Xi Di Sekolah Menegah Kejuruan. Journal Of Multidisciplinary Research And Development. Vol 2. Issue 4, 133-138,2020.

[11] Riduwan, Skala Pengukuran Variabel-Variabel Penelitian. Bandung: Alfabeta, 2010. 
Halaman ini sengaja dikosongkan 